\section{Insulin in the management of diabetes mellitus}

\section{Ruth Theuma BPharm(Hons), Msc Clin Pharm(Aberdeen)}

Senior Clinical Pharmacist, Mater Dei Hospital, Tal-Qroqq, Malta

Secretary, Malta College of Pharmacy Practice

Email: ruth.theuma@gov.mt

\section{Key words}

Insulin, type 1 diabetes mellitus, type 2 diabetes mellitus, insulin analogues, insulin delivery

Insulin is an essential drug used in the treatment of both type 1 and type 2 diabetes mellitus. Depsite this, insulin remains one of the drugs that is disliked by most patients and health-care professionals. It is also a drug that is vey commonly implicated in medication errors. Pharmacists are in an ideal position to give the appropriate information on insulin to patients with diabetes mellitus every time that they come to the pharmacy. More and more patients are being switched to insulin analogues, which have greatly improved the management of diabetes.

\section{Introduction}

Diabetes mellitus refers to a group of metabolic diseases characterised by hyperglycaemia.

It results from defects in insulin secretion, insulin action, or both. ${ }^{1}$ Insulin is secreted from the beta-cells of the pancreas and is the hormone needed to enable
Insulin in type 1 diabetes

Type 1 diabetes results from a cellularmediated autoimmune destruction of the beta-cells of the pancreas with consequent insulin deficiency. ${ }^{1}$ Insulin is required for survival to prevent ketoacidosis, coma and death, ${ }^{3}$ thus the term 'insulin-dependent diabetes' was previously coined to this type of diabetes.

\section{Insulin in type 2 diabetes}

Although insulin was originally developed for the treatment of type 1 diabetes, it has gained more importance in the management of hyperglycaemia in type 2 diabetes. Guidelines suggest that insulin should not be used as last-line treatment when other therapies fail. It should be used early on as an additional therapy to lifestyle interventions and metformin. ${ }^{4}$ Alvarsson et al ${ }^{5}$ showed that earlier insulin use in patients with type 2 diabetes, in contrast to sulphonylurea therapy, helps preserve beta-cell function and promotes better metabolic control with less chance of hypoglycaemia. In the second year of the study, the effectiveness of the oral hypoglycaemic agents that increase betacell function decreased, supporting the concept that beta-cells wear out if they are continuously overworked. ${ }^{5}$ This is not the case when insulin is given as treatment earlier on since it may temporarily prolong endogenous insulin secretion.

Insulin offers an expected decrease in glycosylated heamoglobin ( $\mathrm{HbA1c}$ ) of $1.5-2.5 \%$; which is the largest expected decrease in $\mathrm{HbA1c}$ when compared to other therapies, making it the most effective of diabetes medications in lowering blood glucose. ${ }^{4}$ It is also inexpensive when compared to other classes of anti-diabetic agents. ${ }^{4}$ There is no dose limit with insulin treatment and relatively larger doses are required to overcome the insulin resistance of type 2 diabetes when compared to doses used in type 1.4

Insulin improves the lipid profile but is associated with weight gain of around 2 to $4 \mathrm{~kg} .{ }^{4}$ This weight is partly due to the correction of glycaemia (which presents with weight loss) and partly due to the reduction of glycosuria. ${ }^{4}$ Insulin-induced hypoglycaemia is less frequent in type 2 than in type 1 diabetes. ${ }^{4}$ 


\begin{tabular}{lllrrr} 
Type of insulin & Example & Colour & $\begin{array}{r}\text { Onset of action } \\
\text { (hours) }\end{array}$ & $\begin{array}{r}\text { Peak of action } \\
\text { (hours) }\end{array}$ & $\begin{array}{r}\text { Duration of action } \\
\text { (hours) }\end{array}$ \\
\hline Short-acting & Soluble insulin & Yellow & 0.5 & $1.5-3.5$ & $7.0-8.0$ \\
$\begin{array}{l}\text { Intermediate-acting } \\
\begin{array}{l}\text { Intermediate- and short } \\
\text { acting mixtures }\end{array}\end{array}$ & Isophane insulin & Light green & $1.0-2.0$ & $4.0-12.0$ & $16.0-35.0$ \\
\end{tabular}

\section{Basal and prandial insulin}

It is convenient to think of the insulin dose requirement in physiologic terms consisting of "basal" and "prandial". Basal insulin refers to background exogenous insulin given per unit of time necessary to prevent unchecked gluconeogenesis and ketogenesis. ${ }^{6}$ Basal insulin is the intermediate- or long- acting component of an insulin regimen. Prandial insulin, on the other hand, refers to the insulin that is necessary to cover meals. ${ }^{6}$ This is represented by short- or rapid-acting insulins. In most insulin dose regimens, the intermediate- or long- acting insulins are given together with short- or rapidacting insulins once or twice daily in order to mimic the physiological pattern of endogenous insulin as secreted by the pancreas.

\section{Types of insulin}

Since the landmark discovery of insulin by Fredrick Banting and Charles Best in 1922, huge steps have been made in research and development of insulin preparations. ${ }^{2}$ Early insulin preparations were purified quite crudely from porcine or bovine pancreatic tissue. Today, insulin is mostly made biosynthetically by recombinant DNA technology or genetic engineering of human sequence insulin.
Recent advances on human insulin resulted in the development of the insulin analogues. ${ }^{7}$ These analogues are a genetically engineered form of insulin in which certain amino acids are substituted for those found naturally on an insulin molecule to improve their pharmacokinetic profiles. ${ }^{7}$ There are two types of insulin analogues, the rapid-acting analogues and the long-acting analogues.

Rapid-acting insulin analogues are absorbed faster from the injection site when compared to the conventional soluble insulin. ${ }^{7}$ Thus they readily supply a bolus of prandial insulin required to deal with postprandial elevations in blood glucose. Currently there are three rapid-acting analogues namely aspart, glulisine, and lispro. The more rapid onset of action of these analogues is an advantage over regular human soluble insulin. The latter has to be injected 30-45 minutes before meals to ensure that peak concentrations coincide with the elevated post-prandial glucose levels. In practice patients might tend to inject their insulin at meal times, or on the contrary, inject insulin and then skip or refuse the meal, with the possibility of a hypoglycaemic event. These problems were overcome with the development of the rapid-acting insulins which can be given just before meals.
Long-acting insulin analogues, that is, insulin glargine and insulin detemir are released slowly over time and thus present a constant level of basal insulin or background insulin for the day. ${ }^{7}$ Insulin glargine is designed to have low solubility at neutral $\mathrm{pH}$. It is completely soluble at the acidic $\mathrm{pH}$ of the injection solution. ${ }^{8}$ After injection into the subcutaneous tissue, the acidic solution is neutralised leading to the formation of microprecipitates from which small amounts of insulin glargine are continuously released, providing a smooth, peakless, predictable concentration/time profile with a prolonged duration of action. On the other hand, insulin detemir has a prolonged duration of action since it self-associates strongly at the injection site and binds to albumin via the fatty acid side-chain. ${ }^{9}$ Thus detemir is released more slowly to peripheral target tissues.

Several studies that compared rapidacting insulin analogues with short-acting soluble insulin, and long-acting insulin analogues with isophane insulin, have suggested that insulin analogues reduce hypoglycaemia, particularly at night. ${ }^{10}$

Several insulin preparations are available locally. The conventional ones are listed in Table 1, whereas the insulin analogues are listed in Table 2.

Table 2. Insulin analogues available locally ${ }^{14,15,16,17}$

\begin{tabular}{llrrr} 
Type of insulin & Examples & $\begin{array}{r}\text { Onset of action } \\
\text { (hours) }\end{array}$ & $\begin{array}{r}\text { Peak of action } \\
\text { (hours) }\end{array}$ & $\begin{array}{c}\text { Duration of action } \\
\text { (hours) }\end{array}$ \\
\hline Rapid-acting & Insulin aspart & 0.25 & $1.0-3.0$ & $3.0-5.0$ \\
& Insulin lispro & $0.25-0.50$ & $0.5-2.5$ & none \\
Long-acting & Insulin glargine & 1.00 & $1.0-4.0$ & $15.0-24.0$ \\
Rapid- and intermediate-acting & Biphasic insulin lispro & 0.25 & &
\end{tabular}


Similar preparations of insulin regardless of manufacturer have the same colour on the label. This universal colour code was agreed upon by major insulin manufacturers following an initiative by the International Diabetes Federation (IDF). ${ }^{18}$ Such a colour code helps to reduce confusion for patients with diabetes especially since patients might recognize the type of insulins from the colour on the label. Colour coding also proves helpful for patients who have to buy insulin abroad or from a different source. All parties are now actively working together to produce a colour code for insulin analogues.

Onset, peak, and duration of action are approximate for each insulin product, as there may be variability depending on each individual, the injection site, and the individual's exercise program. ${ }^{16}$

\section{Insulin delivery devices}

For optimal control of patients with diabetes, insulins do not only have to match the endogenous insulin as closely as possible but they must also be formulated and delivered in a way so as to encourage patient adherence.

For many years, the vial and syringe were the standard means of delivering insulin and locally this method is the most popular especially among patients with Type 2 diabetes. However, the syringe carries a stigma and not all patients are

\section{Practice points}

- Insulin should not be used as last-line therapy in type 2 diabetes mellitus but early on as an additional therapy to lifestyle interventions and metformin since it preserves pancreatic function.

- Insulin analogues are produced from genetic engineering of the insulin molecule and are associated with reduced hypoglycaemia especially during the night.

- Rapid-acting insulin analogues can be given immediately before a meal or shortly after if necessary and thus are classified as 'prandial' insulins. They are important to cover the glucose elevations brought about when meals are consumed.

- Long-acting insulin analogues offer a constant 'basal' level of insulin and are designed in a way so as to offer a peakless concentration of insulin in the body.

- Although the syringe and vial are the mostly used insulin delivery system, the insulin pen is discreet, less painful when injecting insulin and easier to use especially for patients with decreased visual acuity. comfortable to use it. This has implications for compliance and glycaemic control.

The introduction of insulin pens in 1985 has offered several advantages to the patient: ${ }^{15}$

- discreet and appears less 'medical'

- injection is less painful since needle is shorter

- less time consuming

- easier to use especially for patients who have impaired eyesight or coordination

- more accurate dosing with an audible click when the dose is dialed

- less wastage of insulin

Better adherence after conversion to pen ( $55 \%$ vs $36 \%$ ), reduced likelihood of
Panel 1. Insulin dispensing practice points

1. Insulin should be stored in the fridge; the vial or cartridge in use should be kept at room temperature and has a shelf life of 4- 6 weeks once punctured..$^{8,9,11-14,17}$ The insulin pen should never be refrigerated.

2. Soluble and isophane insulins can be mixed together in a syringe; soluble insulin is drawn up first and the total volume made up by adding the isophane insulin. ${ }^{12}$ Insulin analogues should not be mixed together. ${ }^{8,14}$

3. The $1 \mathrm{~mL}$ insulin syringe is graduated in 100 units of insulin; the insulin pen gives an audible click every time that it is turned and 1 click is equivalent to 1 unit of insulin being drawn up from the cartidge to the pen. ${ }^{15}$

4. Injection sites should be rotated amongst deltoid, thigh and abdomen; injection in the abdominal wall enures a faster absorption than other injection sites. ${ }^{12}$

5. Soluble insulin, isophane insulin and the biphasic isophane should all be injected half an hour before meals; insulin aspart, insulin lispro and biphasic insulin lispro should be given 15 minutes before a meal but if necessary also immediately before or soon after a meal; insulin glargine can be given once daily at any time but at the same time each day. $8,11,13,14,17,21$ hypoglycaemia episodes, and a decreased likelihood of emergency department visits have been documented. ${ }^{19}$ Insulin pens however are more expensive than the vial and syringe. Insulins cannot be mixed in an insulin pen since only one cartridge at a time can be put in the pen and thus the patient would have to take more injections.

Pens are available in two different forms, with either replaceable cartridges or disposable pre-filled cartridges.

\section{Counselling patients on insulin}

Insulin should be stored in a refrigerator at $2-8^{\circ} \mathrm{C}$ as suggested by the manufacturers. ${ }^{20}$ However, injecting cold insulin can be painful to the patient. To overcome this problem, many providers suggest storing the vial or cartridge of insulin which is in use at room temperature. Insulin kept at room temperature has a shelf life of one month and patients should be advised to write the date of first puncturing on the container. The extra supplies of insulin which are not in use should however be stored in a fridge. Insulin should not be stored in extreme heat (e.g. direct sunlight) or in extreme cold (e.g. in the freezer). Insulin pens should not be stored in the fridge.

Other counselling points that should be communicated to patients whilst dispensing insulin are found in Panel 1.

\section{Conclusion}

Besides counselling the patient with diabetes on storage conditions for their insulin, pharmacists are in a unique 
position to provide clinical input into the management of this chronic condition. Pharmacists may review self-monitoring blood glucose readings of patients, help in the calculation and titration of insulin doses, identify patients with type 2 diabetes who may benefit from the addition of insulin to their regimens, teach the injection technique and provide counselling on avoiding, recognizing and treating hypoglycaemia. ${ }^{7}$

The time when the patient comes for refill of insulin at the pharmacy, is an opportunity for pharmacists to discuss insulin use and diabetes in general and to try to motivate the patients. Surprisingly, less than $40 \%$ of patients with diabetes know their HbA1c levels and only $25 \%$ accurately reported that value. ${ }^{22}$ It is important for patients to know what their HbA1c level is so that they know whether their diabetes is improving or worsening. Patients should also be knowledgeable about the relationship between poor glycaemic control and health risks. ${ }^{7}$

Insulin is in general disliked by the majority of patients. Barriers to its use include a belief that insulin causes complications or death, fear of hypoglycaemia and weight gain, perception of insulin treatment as complicated and difficult, and a feeling of failure from their part if insulin is initiated. ${ }^{15}$
Thus the advantages of adding insulin earlier on in their treatment should be translated to the patient and goals of treatment should be made clear. Patients should be made aware of the advantages of the insulin analogues in mimicking the endogenous insulin system and also in their association of less hypoglycaemic events and less weight gain reports. Moreover, patients with diabetes should be reassured that the initiation of insulin is not a sign of treatment or condition failure. It should be explained to them that diabetes is a chronic condition and that insulin helps to preserve pancreas function. ${ }^{15}$

Pharmacists are now more than ever in a good position to make a difference in the life of a patient with diabetes.

\section{References}

1. American Diabetes Association (ADA), 2007. Diagnosis and classification of diabetes mellitus. Diabetes Care, 30 (1), pp. S42-S47

2. International Diabetes Federation (IDF), 2008. About Insulin [online] Available from: http://www. idf.org/home/index.cfm? printpage $=1 \&$ node $=13$ 96 [Accessed on 16 ${ }^{\text {th }}$ May 2008]

3. World Health Organisation (WHO), 1999. Definition, diagnosis and classification of diabetes mellitus and its complications [online] Available from: http:// www.staff.ncl.ac.uk/philip.home/who_dmg.pdf [Accessed on $12^{\text {th }}$ February 2007]

4. Nathan, D.M., Buse, J.B., Davidson, M.B., et al., 2006. Management of hyperglycaemia in type 2 diabetes: a consensus algorithm for the initiation and adjustment of therapy. Diabetes Care, 29(8), pp. 1963-1972

5. Alvarsson, M., Sundkvist, G., Lager, I., et al., 2003. Beneficial effects of insulin versus sulphonylurea on insulin secretion and metabolic control in recently diagnosed type 2 diabetic patients. Diabetes Care, 26, pp. 2231-2237

6. Clement, S., Braithwaite, S.S., Magee, M.F., et al., 2004. Management of diabetes and hyperglycemia in hospitals. Diabetes Care, 27, pp. 553-597

7. Joffe, D.L., 2008. When, why and how to use insulin analogs (\& with other agents), including patientdriven titration. U.S. Pharmacist, pp. 23-27

8. Electronic Medicines Compendium for the Professional. Specific Product Characteristics. Lantus 100 units/ml solution for injection. 2006 [online] Available from http://www.emc.medicines.org.uk [Accessed on 23 $3^{\text {rd }}$ June 2007]
9. Electronic Medicines Compendium for the Professional. Specific Product Characteristics. Levemir 100 units/ml 2007 [online] Available from http://www.emc.medicines.org.uk [Accessed on $28^{\text {th }}$ May 2008]

10. National Prescribing Centre, 2007. The role of newer insulins in diabetes: Summary. MeReC bulletin, 10 (7), pp. 1

11. Electronic Medicines Compendium for the Professional. Specific Product Characteristics. Actrapid $100 \mathrm{IU} / \mathrm{ml}$ solution for injection 2007 [online] Available from http://www.emc. medicines.org.uk [Accessed on 27 $7^{\text {th }}$ May 2008]

12. British Medical Association and the Royal Pharmaceutical Society of Great Britain, 2007. Insulins. British National Formulary, Number 54. Great Britain: The Pharmaceutical Press, pp. 356363

13. Electronic Medicines Compendium for the Professional. Specific Product Characteristics. Mixtard $30100 \mathrm{IU} / \mathrm{ml} 2007$ [online] Available from http://www.emc.medicines.org.uk [Accessed on $29^{\text {th }}$ May 2008]

14. Electronic Medicines Compendium for the Professional. Specific Product Characteristics. Novorapid $100 \mathrm{U} / \mathrm{ml} 2006$ [online] Available from http://www.emc.medicines.org.uk [Accessed on $23^{\text {rd }}$ June 2008]

15. Marcus, A., 2008. Diabetes care - insulin delivery in a changing world. Medscape Journal of Medicine, 10(5), pp. 120

16. Food and Drug Administration (FDA), 2001. Insulin preparations [online] Available from: http://www. fda.gov/fdac/features/2002/chrt_insulin.html [Accessed on $16^{\text {th }}$ May 2008]
17. Electronic Medicines Compendium for the Professional. Specific Product Characteristics. Humalog Mix25 $100 \mathrm{U} / \mathrm{ml} 2007$ [online] Available from http://www.emc.medicines.org.uk [Accessed on 29 $9^{\text {th }}$ May 2008]

18. International Diabetes Federation (IDF), 2008. Insulin colour code [online] Available from: http:// www.idf.org/home/index.cfm?printpage=1\&uno $\mathrm{de}=$ C767F5 [Accessed on $16^{\text {th }}$ May 2008]

19. Lee, W.C., Balu, S., Cobden, D., et al., 2006. Medication adherence and the associated healtheconomic impact among patients with type 2 diabetes mellitus converting to insulin pen therapy: an analysis of third-party managed care claims data. Clinical Therapeutics, 28, pp. $1712-1725$

20. American Diabetes Association (ADA), Insulin storage and syringe safety information [online] Available from: http://www.diabetes.org/utils/ printthispage.jsp?PageID=TYPEID [Accessed on $16^{\text {th }}$ May 2008]

21. Electronic Medicines Compendium for the Professional. Specific Product Characteristics. Insulatard $100 \mathrm{IU} / \mathrm{ml} 2007$ [online] Available from http://www.emc.medicines.org.uk [Accessed on $27^{\text {th }}$ May 2008]

22. Heisler, M., Piette, J.D., Spencer, M., et al., 2005. The relationship between knowledge of recent $\mathrm{HbA} 1 \mathrm{C}$ values and diabetes care understanding and self-management. Diabetes Care, 28, pp. 816-822 